\title{
Using Computer Based Test Method for the Conduct of Examination in Nigeria: Prospects, Challenges and Strategies
}

\author{
Aliyu Sanni Abubakar \\ National Institute for Legislative Studies (NILS), National Assembly, Abuja-Nigeria \\ Email: alisani78@yahoo.com Tel: +2348032712006. \\ Francis Ojo Adebayo \\ Fiscal Policy Analysis Centre, Abuja-Nigeria \\ Email: francisadebayo31@yahoo.com Tel: +234-803-240-0062.
}

Doi:10.5901/mjss.2014.v5n2p47

\begin{abstract}
In Nigeria there had been a growing concern about the conduct, authenticity and reliability of examinations especially during the process of selecting qualified prospective candidates into Nigerian universities. It is in this regard that the Joint Admission and Matriculation Board (JAMB) introduced the computer-based testing (CBT) with the objective of eliminating all forms of examination malpractices and promote the use of electronic testing in Nigeria. This study therefore seeks to identify the prospects and challenges that will pose threats to the success of adopting CBT in all examinations and how to neutralise them. Secondary data notably textbooks, academic journals, conference papers, internet materials among others were primarily utilized. The study finds that the adoption of CBT in Nigeria faces ten critical challenges amongst this are economic factor, security, Software; Poor ICT culture, policy and implementation; and power failure. Therefore, the study identify educational presentation on CBT, public relation campaign, web campaign, post test feed-back, regular power supply, implementation of ICT policy etc as approaches to defuse the challenges.
\end{abstract}

Keywords: Computer-Based Test, Paper Pencil Test, ICT, JAMB

\section{Introduction}

Teaching and learning are constantly being migrated to several ubiquitous platforms. The World Wide Web has therefore become an indispensable tool in the administration of pedagogy. This development has led to accelerated availability of educational resources and the promotion of collaboration across different research and educational institutions. A significant component of this innovative trend is the adoption of web-based technology driven assessment of students. It is becoming commonplace to see institutions across the educational strata adopt computer-based tests (CBT) and assessment to admit or screen students for entrance into Nigerian institutions (Sadiq and Onianwa, 2011). However, this is mode of conducting examination is a new phenomena in Nigeria.

The use of CBT for entrance examinations in education, military training, and certification examinations by professional groups and promotional examinations in various stages and categories of life cannot be overemphasized. Erle, at el. (2006) cited by Olumorin et al. (2013) noted that CBT has gained popularity as a means of testing with largescale professional examinations such as the United States Medical Licensing Examination (USMLE) in 1999. However, the popularity emerged through the post UME and University main examinations in Nigeria. Other institutions such as the University of Ilorin, Federal University of Technology, Akure and Federal University of Technology, Minna are maximizing the use of CBT as tool for undergraduate and postgraduate assessments.

The inclusion of ICTs in education is required to re-consider and re-think, modify or change the traditional examination methods. However, these have reduced the burden of teachers and facilitate the conduct of examinations purposefully. Computer-based examinations can be used to promote more effective learning by testing a range of skills, knowledge and understanding. Also, accessing and managing of information and managing and developing communication skills are possible to assess online which cannot be assessed in regular essay based examinations (Brown, Race, \& Bull, 1999; cited by Mubashrah et al., 2012).

Computer-based tests offers several benefits over traditional paper-and-pencil or paper-based tests. Technology 
based assessment provide opportunities to measure complex form of knowledge and reasoning that is not possible to engage and assess through traditional methods (Bodmann and Robinson, 2004). In Nigeria, employers now conduct aptitude test for their job seekers through electronic means; the universities and other tertiary institutions are registering and conducting electronic examination for their students through the internet and other electronic and networking gadgets. Similarly, different examination bodies in the country such as West Africa Examination Council (WAEC), National Examination Council (NECO), National Board for Technical Education (NABTEB), and National Teachers Institute (NTI) among others register their students through electronic means (Olawale and Shafi'l, 2010).

Computer and related technologies provide powerful tools to meet the new challenges of designing and implementing assessments methods that go beyond the conventional practices and facilitate to record a broader repertoire of cognitive skills and knowledge (Mubashrah et al., 2012). In the past, various methods was employed in examining the ability of an individual, starting from oral to written, practical to theoretical, and paper and pencil to electronic. The present ICT means of examining students in Nigeria is the use of electronic systems in place of manual or paper method which was characterized by massive examination leakages, impersonations, demand for gratification by teachers, bribe-taking by supervisors and invigilators of examinations (Olawale and Shafi'l, 2010).

Recently, the Joint Admission and Matriculations Board (JAMB) conducted the 2013 edition of the Unified Tertiary Matriculation Examination (UTME) with three test options-the traditional Paper Pencil Test, Dual-Based Test and Computer-Based Test. The DBT and CBT which are a novel introduction were largely successful in spite of some challenges especially in the area of infrastructure. However, the JAMB Executive Registrar, Professor Dibu Ojerinde, announced that from 2015; CBT will be used to conduct all UTME. He noted that the objectives of the e-testing was to ensure 100 per cent elimination of all forms of examination malpractice that had been a major challenge in the conduct of public examinations in the country (see Vanguard, $8^{\text {th }}$ November, 2012).

It is against these backdrops that this study aims to achieve two major objectives, to look into the prospects of using CBT in Nigeria and its challenges and strategic plan to adopt for implementation. The study proceeds as follows. Section 1 is the introduction. Section 2 offers an overview of examination assessments in Nigeria. Sections 3 present a brief review of literature. Section 4 expatiated on the prospects, and challenges of the CBT in Nigeria. Strategies for implementation and Conclusions are presented in Section 6.

\section{Overview of Examination Assessments in Nigeria}

The predominant mode of student's assessment in Nigeria is the traditional method. In this method, students are assessed using paper and pen on cognitive abilities. This method of assessment has imposed serious limitations to the effectiveness of the method. E-examination can be used to assess cognitive and practical abilities. Cognitive abilities are assessed using e-testing software; practical abilities are assessed using e-portfolios or simulation software (Yu, 2004; cited by Sadiq and Onianwa, 2011).

Presently, the traditional method in Nigeria is characterized by different form of examination malpractices such as bringing in unauthorised materials, writing on currency notes and identity cards, spying of other candidates in examination hail, substitution of answer sheets and change of examination scores or grades. Others include, impersonation, leakage of questions to students before the examination, conniving with supervisors and school authorities to cheat, body writing or tattoo in which students especially females write on hidden parts of their bodies (see Adamu, 1998; Fagbemi 2001; Jacob \& Lar, 2001; cited by Olatoye, n.d.). Alabi, Issa and Oyekunle (2012) corroborated this by identifying the PPT with many problems such as: Tedious processes as the examination was conducted at various and distant centres simultaneously and marked manually; high risks of accidents during travels by both the staff involved and the prospective students for the paper examination; cost of conduct of the examination on the part of the examination bodies including honoraria for invigilators, coordinators, markers collators and other allied staff; subjective scoring and plausible manipulation of results; late release of results and missing grades; bank draft method of payment by candidates riddled by fraud, loss of money, stress and trauma.

The above steps are very much prone to violation at any stage and it also involved heavy resources in terms of manpower and funding. Davey (2011) noted that a wide assortment of options are now available for using a computer to present information, facilitate interaction, and collect responses in ways not possible with traditional text-based items. The question is then how (or whether) these capabilities can be used to materially and substantively improve measurement.

Assessment is central to the practice of education. For students, good performance on 'high-stakes' assessment gives access to further educational opportunities and employment. For teachers and schools, it provides evidence of 
success as individuals and institutions. Assessment systems provide the ways to measure individual and institutional success, and so can have a profound driving influence on systems they were designed to serve (Jim and Sean, 2006). The intimate association between teaching, learning and assessment is illustrated in Fig 1 below.

Fig. 1: Relationship between Teaching, Learning and Assessment

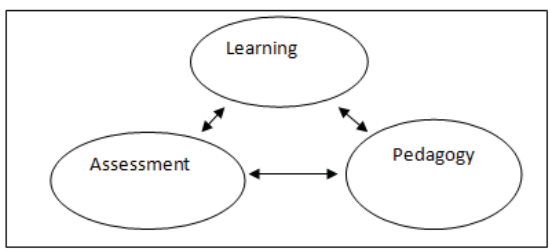

Source: Jim and Sean (2006).

Currently, examinations in Nigeria are a disaster to both parents, students, the government and teachers. It is generally not a true reflection of students' knowledge and capabilities to a great extent and in many cases a show of shame going by the number of ceased and cancelled results released by the examination conducting bodies. In fact a state of emergency needs to be declared on examinations approach in Nigeria. ${ }^{1}$

Examination malpractice in Nigeria and indeed in many countries of the world is already a cankerworm. It has attained an alarming proportion and also endemic to educational systems all over the world. The problem is hydraheaded and has defied most recommended solutions. The categories of people involved in examination malpractices are many and the forms of examination malpractices are almost without end. It takes place at all educational levels. It is a concern to all stakeholders in education and it takes place in both internal and external examinations. Children, youths and adults are all involved in the act (Olatoye, n.d.).

The World Bank Group (2002) cited by (Olatoye, n.d.) also reported that examination malpractices may even include creation of ghost centres where candidates can sit for examinations with the support of helpers and without supervision. Also, deliberate award of certificates to candidates who did not even sit for examinations has been reported. In the past, it used to involve only examination officials, but in recent years, it included printers and candidates with highlevel skills in technology. Examination malpractices technically tend to weaken the validity of any examination and the results become unreliable and worthless. When this happens, it is difficult to assess candidates' performance based on the certificate they hold.

Examinations are conducted every term for 3 terms in the primary and post-primary institutions in Nigeria. It is held twice per session in the tertiary institutions representing the two semesters per session. It follows a standard pattern and marking scheme. The examination proper is supervised by a team of invigilators, para-military men, civil defense and some other adhoc staffs recruited as the case may be. ${ }^{2}$

Examinations could be internal or external. It could be oral, written or both. Examples of internal examinations are continuous assessment tests, terminal, semester and annual or promotion examinations. Examples of external (public) examinations common in Nigerian schools are Common Entrance Examination for admission into secondary school. Others include school certificates examination conducted by West African Examination Council (WAEC) and National Examination Council (NECO), the Joint Admission Matriculation Board (JAMB) and National Teachers' Institute (NTI) conduct admission tests into tertiary institutions while the National Business and Technical Examination Board (NABTEB) conducts professional examinations for teachers and technicians, respectively (Oredein, n.d.).

The threat of examination malpractices on the validity of examination has made some examination bodies to give excessive attention to checking examination malpractices even at the test development stage. Joint Admissions and Matriculation Board (JAMB) administers different question formats in which questions do not follow the same order. The alternatives under each question in a format do not also follow the same order. However, different examination bodies have put up efforts at combating the scourge of examination malpractices. It seems that candidates too are not relenting in frustrating and voiding all efforts by these bodies (Olatoye, n.d.).

\footnotetext{
1 See http://www.nuhafoundation.org/home/blog/bloggingentries/2013/adult/changing_the_mode_of_conducting_examinations_in nigeria_b_adazie\#.UIKNMVPFZxE

2 See http://www.nuhafoundation.org/home/blog/bloggingentries/2013/adult/changing_the_mode_of_conducting_examinations_in _nigeria_b_adazie\#.UIKNMVPFZXE
} 
Fagbemi (2001) cited by Olatoye (n.d.) reported efforts adopted by WAEC to fight malpractices. These efforts are public enlightenment campaigns, information to students on rules and regulations guiding its examinations, punitive action on candidates and WAEC staff involved in malpractices and creation of a whole department headed by a deputy registrar to handle cases of malpractice. As a way of reducing examination malpractices, Continuous Assessment (CA) has been introduced in Nigeria. The scores in the CA could be inflated as the school teachers provide them. National Examinations Council (NECO) has devised a means called 'technical failure'. If candidate score 70/70 in their examination and less than $12(40 \%$ of 30$)$ in CA or no CA at all, they have failed. To pass NECO examinations, a candidate must score at least $28(40 \%$ of 70$)$ in the final examinations.

In addition, the Nigerian university system began the post-JAMB Screening Examinations in 2005 as a way of validating the scores obtained by candidates in the University Matriculation Examinations (UME) organized by the Joint Admissions and Matriculation Board (JAMB) (Alabi, Issa and Oyekunle, 2012). In relation to this, Electronic Test Company (ETC) introduced Computer based test into Nigeria education system for universities, schools, and companies. The introduction of CBT enables educators and trainers to author, schedule and deliver tests and examinations. As at 2011, ETC centers have locations at; University of Ilorin , Kwara State, Oba Akran Avenue Ikeja, Lagos, University of Lagos, Lagos, University of Agriculture, Makurdi, Federal University of Technology, Minna, University of Maiduguri, University of Ibadan, Oyo State. Additional centers' are currently under construction all over Nigeria with expectation to have up to 25,000 computers located in various centers' throughout the country (Oladipo 2009; cited by Olumorin et al., 2013).

Ayo, Akinyemi, Adebiyi \& Ekong (2007) cited by Adegbija et al., (2012) proposed a model for e-examination for the Joint Admissions Matriculation Board (JAMB) as a way of curbing examination irregularities. Thus, the adoption of eexaminations by many institutions in Nigeria since the conventional examination is plagued with several pitfalls such as examination leakages, impersonations, inadequate supervisors, demand for gratification by markers so that results can be influenced, bribe taking by supervisors or invigilators, and the most devastating of these is the delay and/or in many cases, non-release or delay of examination results especially where there are large classes or public examinations.

\section{Brief Review of Literature}

A large body of literature already exists on online assessment using computers and paper. For example, Bodmann and Robinson (2004) conducted an experimental study to compare speed and performances differences among CBTs and PPTs. In the experiment fifty-five undergraduate students enrolled in the subject of educational psychology, participated in the studies which were already familiar with CBTs. Both CBTs and PPTs contained 30 MCQs items with 35 minute of time limit. The findings observed that undergraduates completed the CBT faster than PBT with no difference in scores. Research outcomes have thus supported the fact that when students are motivated and testing conditions are equivalent, there are no differences between the scores obtained via CBT or PPT (Lynch, 1997 \& Marson, Patry, and Berstein, 2001; cited by Alabi, Issa and Oyekunle, 2012).

Gary (2008) at the University of New South Wales, Sydney studied the effect of online formative assessment on learning. The outcomes support the contention that integrated well designed online formative assessments can have significant positive effects on learning. Web based formative assessments also support equity and inclusiveness by allowing students to attempt each assessment anonymously on multiple occasions at any time.

Lim, et al., (2006) examined medical students' attitude about CB Vs PB testing in Singapore. Through an online survey, 213 (53.5\%) final-year MBBS students were tested out of which 91 (79.8\%) preferred CBT, 11 (9.6\%) preferred P\&P format and 12 (10.5\%) were un-sure. The study found that 42 indicated that 42 liked CBT because of good quality of images and independent of assigned seating positions; 22 liked CBT because they could proceed at their own pace; one stated that CBT examinations was fun; 4 enjoyed the convenience of $\mathrm{CBT}$ and 6 cited "equality" as the reason they preferred CBT over P\&P testing.

Karadeniz (2009) studied the impact of paper based, web based and mobile based assessment on students' achievement. A group of 38 students were experimented for 3 weeks. Significant differences were found between the scores achieved by the students in second week but not in first week. The paper revealed that students had positive attitude towards web based and mobile based assessment due to ease of use, comprehensive and instant feedback. Moreover, most favoured tests were web based and the least favoured were paper based.

Calarina and Wallace (2002) investigated to confirm several key factors in CBT versus PPT assessment. Factors of the study were content familiarity, computer familiarity, competitiveness, and gender. The study used a post-test only designed with one factor, test mode (Computer-based and Paper-based). Students' score on 100-item multiple choice 
items and students' self-report on a distance learning survey were treated as dependent variables. Four sections of Computer Fundamental Course consisting of 105 students were selected as sample of the investigations. Results showed that CBT delivery impacted positively on students' scores as compared to PPT. The study found that the CBT group out-performed the PPT group. Gender, competiveness, and computer familiarity were not related to this performance difference, though content familiarity was.

Jim and Sean (2006) concluded that the e-assessment can be justified in a number of ways. It can help avoid the meltdown of current paper-based systems; it can assess valuable life skills; and it can be better for users. For example, by providing on demand tests with immediate feedback and perhaps diagnostic feedback, and more accurate results via adaptive testing, it can help improve the technical quality of tests by improving the reliability of scoring. Therefore, a proper preparation of the students for the exam via an introduction to the software, a CBT could be a good method to curtail examinations malpractice effectively.

A study by Ayo (2007) on Nigerian University stated that $81.3 \%$ of the applicants were computer literate, while the remaining $18.7 \%$ were guided through the examination. The total number $1023(75.7 \%)$ of respondents who participated in the e-examination conducted in Covenant University took electronic examination for the first time and as such found the examination easy, a few found it a little challenging but adjusted with time. The study revealed that only 327 (24.2\%) of the applicants had not been involved in any form of electronic examination before, and found it difficult.

\section{Prospects and Challenges of Computer Based Test in the Conduct of Examination in Nigeria}

Computer based test has been immensely advocated mainly by JAMB among other examination bodies in Nigeria. The entire process has its strengths and weaknesses. However, this section is divided into three categories, namely prospects, challenges of CBT in the conduct of examination in Nigeria and strategies for policy makers:

\subsection{Prospects of CBT in the Conduct of Examination in Nigeria}

CBT have advantages over PPT testing, both for states that run the assessment programs and for the students who participate in them. These advantages are recognized by the U.S. Department of Education, which is one of its major initiatives (Race to the Top Assessment Program), encouraged the development of CBT (Thurlow et al., 2010). However, advocates of CBT have identified many positive prospects of this approach to assessment as follows 3 :

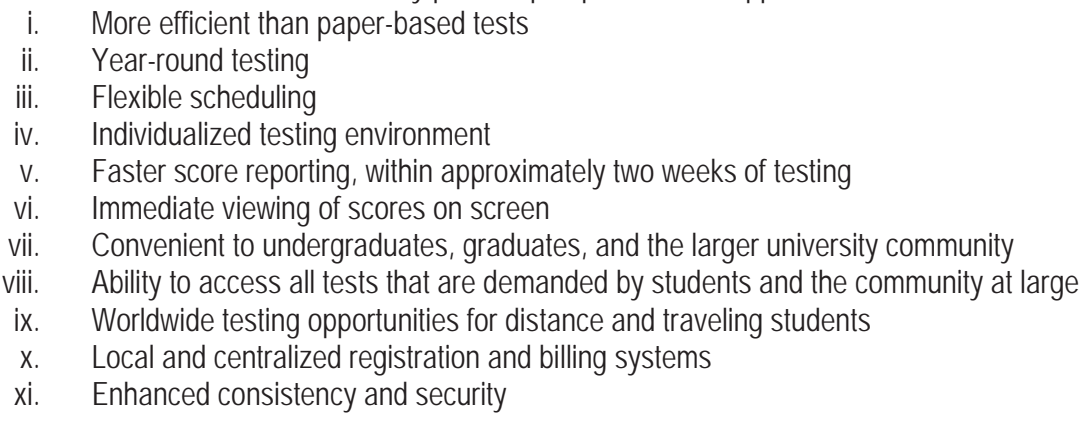

\subsection{Challenges of CBT in Nigeria}

Computer Based Test is still a new phenomenon in Nigeria. However, CBT in the conduct of examination in Nigeria poses a lot of challenges. These challenges have been categorised into ten factors for clarity and proper presentation below:

Economic factor: ICTs remain a low financial priority in most educational systems in Africa. Most countries in the region lack resources for a sustainable integration of ICTs in education (Evoh, 2007; cited by Adomi and kpangban, 2010). This has made it difficult for Nigerian educational system to acquire and install ICT facilities for the use of teachers and students. Nigeria has over 6,000 public secondary schools. Majority are short of books, paper and pencils. Many of the schools lack adequate infrastructure such as classrooms and only few are equipped with television or radio. Apart

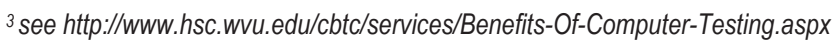


from the basic computers themselves, other costs associated with peripherals such as printers, monitors, paper, modem, extra disk drives are beyond the reach of most schools in Nigeria. The schools cannot also afford the exorbitant internet connection fees (Aduwa-Ogiegbaen and lyamu, 2005). Therefore, public budgets do not permit significant provision for these initiatives.

Security factor: Existing biometric and non-biometric e-examination system involved sending examination questions to the e-exam centre from the examination bodies, where operator will then enter the questions into the system. The biometric system consists of picture box and fingerprint scanner that collect the biometric data of the candidates (Olawale and Shafi'i, 2010). But due to the transferring of the question involved, the security of the system is at risk. There may be a higher risk of (e-) cheating, e.g. by hacking the database of the question items, a risk of total loss of examination data or a lower security of sensitive personal data (Olumorin et al., 2013) is inevitable.

Poor ICT culture, policy \& implementation: The ICT revolution is yet to attain that critical mass required for it to register the necessary impact in the teaching, student and civilian population nationwide. Whilst Obafemi Awolowo University (OAU), University of Jos (UNIJOS), and the Federal College of Education in Omoku could be said to be in the vanguard, the majority of Nigeria's universities, polytechnics, nursing and midwifery schools, and colleges of education lack computers (Osei, 2007).

The absence of policy has not helped co-ordinate ICT projects and programmes being carried out separately by various agencies operating in the education sector, and will lead to resource wastage and duplication (Osei, 2007). The Nigerian Federal Government's 1988 policy introduced computer education to the high schools (Okebukola, 1997; cited by Adomi and kpangban, 2010). The only way this policy was implemented was the distribution of computers to federal government high schools, which were never used for computer education of the students. No effort was made to distribute computer to state government or private schools.

Poor ICT funding: E-learning and ICT application to education in general may come of age in Nigerian schools. Schools in Nigeria are not given adequate funds to provide furniture, requisite books, laboratories and adequate classrooms let alone being given adequate funds for high-tech equipment (computers) and Internet connectivity (AduwaOgiegbaen \& lyamu, 2005). Many of the lecturers in these public institutions have to go to commercial cyber cafés before they can have access to a computer. The private universities are better off since majority of them, such as the ABTIAmerican University of Nigeria (AAUN) has 24-hours Internet connectivity on campus, and each student is provided a laptop with the cost factored into the fee structure (Osei, 2007).

Poor information infrastructure: The lack of requisite telecommunications infrastructure capable of transporting multimedia messaging (Osei, 2007) is another major challenge. Research confirms that one among the impediment to the use of ICT in Nigerian school is poor information infrastructure. It has been reported by South-wood (2004) cited by (Adomi and kpangban, 2010) that more than $40 \%$ of the population of Africa is in areas not covered by telecom services. Schools located in such areas will experience ICT connectivity problems.

Power failure: The lack of electric power and telecommunications infrastructure in a considerable part of the country is a problem. Mobile telecommunication currently covers $60 \%$ of the national territory, but mobile telephone companies generally power their base stations using private electric power generators since the Power Holding Company of Nigeria (PHCN) is unable to guarantee supply of power. This phenomenon is prevalent nationwide and constitutes the bottleneck to effective countrywide deployment of ICT in education (Osei, 2007).

Computer equipment was made to function with other infrastructure such as electricity under "controlled conditions". For the past fifteen years, Nigeria has been having difficulty providing stable and reliable electricity supply to every nook and cranny of the country without success. Currently, there is no part of the country, which can boast of electricity supply for 24 hours a day except probably Government Reserves Areas. In rural Nigeria, most inhabitant do not have access to electricity, thereby denying rural schools opportunity to benefit from the use of electronic equipment such as radio, television, video recorders and computers. The few Internet access available in Nigeria is found in urban centers. These environmental realities are difficult to manage because stable electricity are lacking in many urban homes and rural areas (Aduwa-Ogiegbaen and lyamu, 2005).

Inadequate ICT manpower/skills: Nigeria does not only lack information infrastructure, it also lacked the human skills and knowledge to fully integrate ICT into secondary school education. There is acute shortage of trained personnel in application software, operating systems, network administration and local technicians to service and repair computer facilities. Those who are designated to use computers in Nigeria do not receive adequate training, and at worst, do not receive any training at all (Okebukola, 1997; Anao, 2003; cited by Aduwa-Ogiegbaen and lyamu, 2005). Most of the school teachers lack the skills to fully utilize ICT in curriculum implementation hence, the traditional chalk and duster approach still dominates in secondary school pedagogy. Information transfer using ICT is minimal or non-existence in 
secondary schools in Nigeria.

Software factors: There is no doubt that the ultimate power of technology is the content and the communication. Software developers and publishers in the developed countries have been trying for long to develop software and multimedia that have universal application, due to the differences in education standards and requirements. However, these products do not integrate into curriculum across countries. Salomon (1989) cited by Aduwa-Ogiegbaen \& lyamu (2005) stated that there are clear indications from many countries that the supply of relevant and appropriate software is a major bottleneck obstructing wider application of the computer. Even if Nigeria tries to approach this software famine by producing software that would suit its educational philosophies, there are two major problems to be encountered. First, the cost of producing relevant software for the country's educational system is enormous. Second, there is dearth of qualified computer software designers in the country.

Gender equity: Nigeria is confronted with a persistent problem in girls' education, principally in the northern and rural areas, because of traditional beliefs and roles reserved for girls in the family and religious set-ups. This has prompted government to embrace gender equity programmes in education. However, school enrollment disparities still exist in the rural and northern areas (Osei, 2007). Students with insufficient computer literacy or differences in computer performance may be disadvantaged despite their expertise/understanding in the course content (Charles et al., 2013).

Accessibility to the internet: In Nigeria there are few Internet providers that provide Internet gateway services to Nigerians. Many of these internet providers (i.e. companies) provide poor services to customers who are often exploited and defrauded. The few reputable companies which render reliable services charged soaring fees thus limiting access to the use of the Internet. The greatest technological challenge in Nigeria is how to establish reliable cost effective Internet connectivity. In a country where only about $0.6 \%$ of the populace has home personal computers, the few reliable Internet providers who have invested huge sum of money in the business have a very small clientele. They have to charge high fees in order to regain their investment in reasonable time. Also, secondary schools in rural areas lack access to internet facilities due to adequate electricity supply. Nigeria is lagging behind other African countries such as Senegal, Uganda and South Africa who are already helping secondary school students to become better information users. Worst still, all Internet service providers in Nigeria are based in the urban areas (Aduwa-Ogiegbaen and lyamu, 2005).

\section{Strategies and Conclusion}

This section provides the strategies for policy makers in the implementation of $\mathrm{CBT}$ in the conduct of examination in Nigeria and conclusion.

\subsection{Strategies for Policy Makers}

Computer-based testing (CBT) is an efficient way for test sponsors to provide a secure, consistent environment for certification and licensure while significantly enhancing the candidate experience. It is common for testing volumes to increase after a full conversion from PPT to CBT, often as a result of the availability of a greater number of testing locations and more flexible scheduling and testing opportunities. Migration from PPT to CBT does affect candidate behavior and it is possible for some testing programs to experience brief reductions in demand triggered by candidate apprehension regarding CBT. This sometimes results in either a last-minute increase in testing during final PBT administrations or candidate procrastination to the last available computerized testing date. Therefore, the question facing licensing organizations is how to keep test volumes up and candidate uncertainty down when migrating from a PPT to CBT.

The key to mitigating test volume risk and ultimately driving an increase in demand is ongoing marketing, candidate education and outreach. In terms of promoting the new computerized testing program, marketing and effective communication can have a significant impact on stakeholder acceptance of CBT and comfort with its use. In order to allay candidate fears and minimize questions, it is prudent to launch a communications campaign early in the conversion process that directly addresses constituent concerns and promotes sustainable program interest.

Some of the more commonly utilized and effective candidate communications outreach initiatives include4:

Adequate educational presentations on CBT: Educational presentations should focus on information regarding the benefits of $\mathrm{CBT}$ for testing candidates. They may present information on new content areas, changes in test structure or

4 See https://www.prometric.com/en-us/news-and-resources/reference-materials/pages/Converting-from-Paper-Based-to-ComputerBased-Testing.aspx 
format, system navigation, and other program changes (e.g. test duration, question review, break policies). They may also give candidates a glimpse of the new "look and feel" of the test. Presentations or demonstrations may be given at conferences, user group meetings or other relevant forums, as well as via other mediums such as via a web conference.

Public relations campaign: A targeted public relations program will strive to promote the value of computer-based delivery and benefits to candidates, such as same-day exam scoring or on-demand scheduling. The campaign may include media relations, speaking opportunities and special events components.

Website campaign: A website campaign may include a webcast explaining and demonstrating any differences between paper-based and computer-based testing. It could explain to candidates a sample of CBT showing them where and how to navigate through the exam and familiarizing them with the layout and content. The campaign may also include a tutorial on new operational procedures associated with the CBT program, including registration and scheduling processes and site administration policies.

A "Test Drive" tutorial: Test drive provides candidates with a real world, end-to-end practice run before the date of their scheduled test. In 30 minutes, the candidate will experience a complete run of the testing experience they will encounter on their actual testing day. During the test drive, the candidate will experience the scheduling and registration process, walk-through the site check-in procedures, meet the test center staff, familiarize himself or herself with the physical location and environment at the test center, and sit for a live 15-minute sample test with generic content. The goal of this program is to familiarize candidates of certain types of testing programs with the end-to-end CBT testing process prior to the day of administration, allowing the candidate to focus all of his or her attention on demonstrating mastery of the subject matter of the test.

Testimonials: Testimonials and "lessons learned" from other candidates who've already had the experience can be passed along to promote the benefits of the new test from candidate, partner or administrator perspectives.

Post-test feedback: A post-launch survey of test takers can be used to improve future versions of the test and associated test administration processes. The survey can be executed via the Internet immediately following the test, via telephone or mail or via test candidate focus groups. Candidates may provide feedback on any of the following: registration, scheduling, site administration, security, content, navigation, functionality, score reporting, fees and overall satisfaction.

Regular power supply: Government should work towards stabilizing electricity supply in Nigeria by encouraging more private partnership in the power business.

Implementation of ICT policy: The government should ensure that the national ICT policy objectives are translated into reality and also set up a committee that will be headed by the Minister of Communication Technology to monitor the implementation. The policy should ensure that effort are been made to distribute computer to state government and selected private schools.

Adequate ICT training: Adequate ICT training and awareness should be given to the students and staff prior to the period of e-testing. Secondary school teachers in Nigeria need to be trained on educational technologies as well as trained workers that will install, maintain and support these systems. People need to be trained in instructional design to overcome the challenges in the area of dearth of qualified computer software designers in the country.

Taking any or all of these steps to reach out to candidates in advance of a newly computerized test is critical to easing the transition. The main goal of each of the initiatives above is to keep candidates informed.

\subsection{Conclusion}

Experience has shown that examination malpractices have been the bane of Nigeria's education system as both parents and teachers assists students in the task of this crime. This ugly state of affairs has continually robbed-off on both the standard and out-come of education in the country leading to a widespread call for a total overhaul and sanitisation of the entire educational system. As a result, the call for the adoption of the electronic/computer-based tests is a right step in the right direction. However, the process requires an appreciable level of strategies to enable students/candidates meet the challenges posed by CBT. Nonetheless, no human activity goes without its teething problems but consistency brings about success. Best practice experiences revealed some level of success after initial challenges. However, Nigeria would find the utilization of CBT worthwhile. This will not only reduce malpractices but would ensure prompt or timely release of examination results. It will also ensure that students take their studies seriously and discard the idea of planning for malpractices. 


\section{Reference}

Olawale and Shafi'i M.A. (2010), E- Exams System for Nigerian Universities with Emphasis on Security and Result Integrity, The Seventh International Conference on e-learning for knowledge- Based Society, Thailand.

Adegbija, M.V., Fakomogbon, M.A. \& Daramola, F.O. (2012), The New Technologies and the Conduct of E-Examinations: A Case Study of National Open University of Nigeria. British Journals ISSN 2047-3745, Vol. 3 (1), 60-61.

Adomi, E.E. and Kpangban, E. (2010), Application of ICTs in Nigerian Secondary Schools. Retrieved May 18, 2013 from http://www.webpages.uidaho.edu/ mbolin/adomi-kpangban.htm

Aduwa-Ogiegbaen, S. E., and lyamu, E. O. S. (2005), Using Information and Communication Technology in Secondary Schools in Nigeria: Problems and Prospects. Educational Technology \& Society, 8 (1), 104-112.

Alabi, A. T., Isaa, A. O., and Oyekunle R. A. (2012), "The Use of Computer Based Testing Method for the Conduct of Examinations at the University of Ilorin", International Journal of Learning \& Development, ISSN 2164-4063 2012, Vol. 2, No. 3.

Ayo C. K. (2007), The Prospects of e-Examination Implementation in Nigeria. Turkish Online Journal of Distance Education-TOJDE 2007; 8: Article 10.

Bodmann, S. M. and Robinson, D. H. (2004), Speed and Performance Differences among Computer Based and Paper-Pencil Tests. Journal of Educational Computing Research, 31(1), 51 - 60.

Brakel, P.A., and Chisenga, J. (2003), Impact of ICT based distance learning: The African story. The Electronic Library 21 (5), $476-486$.

Bugbee, A. C. (1996), The equivalence of paper-and-pencil and computer- based testing. Journal of Research in Computer Education, 28(3), 282-299.

Davey, T. (2011). Practical considerations in computer-based testing. Educational Testing Service. Retrieved on October $2^{\text {nd }} 2013$ from http://www.ets.org/Media/Research/pdf/CBT-2011.pdf

F.I. Sadiq and Onianwa C.U (2011), Towards a Scalable Web Assessment System for Post University Matriculation Examination in Nigeria. African Journal of Computer \& ICTs Vol. 4, No. 2. pp 25-30. Retrieved on October $4^{\text {th }} 2013$ from http://www.ajocict.net.

Jim R. and Sean, M. (2004), Literature Reviews of E-assessment, Futurelab Series, Report 10: ISBN: 0-9544695-8-5. Retrieved on October $4^{\text {th }} 2013$ from http://hal.archives-ouvertes.fr/docs/00/19/04/40/PDF/ridgway-j-2004-r10.pdf

Karadeniz, S. (2009), The impacts of paper, web and mobile based assessment on students' achievement and perceptions. Scientific Research and Essay, 4(10), 984 - 991. Retrieved July 15, 2013 from http://www.academicjournals.org/sre

Lim, E., CH., Ong, B., K. C., Wilder-Smith, E., PV., Seet, R., CS. (2006), Computer-based Versus Pen and-paper Testing: Students' Perception. Ann Acad Med Singapore, 35 (9), 599-603.

Olatoye, R. A. (n.d.), Checking the menace of examination malpractice: A call for more teaching and learning in schools. Retrieved on July 182013 from http://naere.org.ng/journal/CHECKING_MENACE_EXAMINATION_MALPRACTICE.pdf

Olumorin, O. C., Fakomogbon, A. M., Fasasi, A. Y., Olawale, O. C., Olafare, O. F. (2013), "Computer based tests: a system of assessing academic performance in university of Ilorin, llorin, Nigeria", American Academic \& Scholarly Research Journal Vol. 5, No. 2.

Oredein, A. O. (n.d.), Checking Examination Malpractice in Nigerian Schools. Accessed on July 152013 from: http://naere.org.ng/journal/checking_examination_malpractice_nigerian_schools.pdf

Osei, A. T. (2007), ICT for Education in Nigeria, Survey of ICT and Education in Africa. Nigeria Country Report. Accessed on 18/9/2013 from http://www.infodev.org/infodev-files/resource/InfodevDocuments 422.pdf

Thompson, S., Thurlow, M., \& Moore, M. (2003), Using computer-based tests with students with disabilities (Policy Directions No. 15). Minneapolis, MN: University of Minnesota, National Center on Educational Outcomes.

Thompson, S. J; Thurlow, M. L; Quenemoen, R. F., \& Lehr, C. A. (2002), Access to computer-based testing for students with disabilities (Synthesis Report 45). Minneapolis, MN: University of Minnesota, National Center on Educational Outcomes.

Thurlow, M., Lazarus, S. S., Albus, D., \& Hodgson, J. (2010), Computer-based testing: Practices and considerations (Synthesis Report 78). Minneapolis, MN: University of Minnesota, National Center on Educational Outcomes.

Vanguard (2012), JAMB Computer Based Test in 2013: Stakeholders react. November 8 www.vanguardngr.com.

Velan, G. M; Jones, P; McNeil, H. P. \& Kumar, R. K. (2008), Integrated online formative assessments in the biomedical sciences for medical students: benefits for learning. BMC Med Educ; 8:52.

Whittington, D., Bull, J., \& Danson M. (2000), Web-Based Assessment: Two UK Initiatives. The Sixth Australian World Wide Web Conference, Rihga Colonial Club Resort, Cairns, 12-17 June 2000,Australia. Retrieved May 12, 2013 from http://www.ausweb.scu.edu.au/aw2k/papers/index.html. 
